\title{
Reactive Chemical Vapor Deposition Method as New Approach for Obtaining Electroluminescent Thin Film Materials
}

\author{
Valentina V. Utochnikova, ${ }^{1,2}$ Oxana V. Kotova,, ${ }^{1,3}$ Andrey A. Vaschenko, ${ }^{2}$ \\ Leonid S. Lepnev, ${ }^{2}$ Alexei G. Vitukhnovsky, ${ }^{2}$ and Natalia P. Kuzmina ${ }^{1}$ \\ ${ }^{1}$ Laboratory of Chemistry of Coordination Compounds, Chemistry Department, Lomonosov Moscow State University, \\ 1-3 Leninskie Gory, 119991 Moscow, Russia \\ ${ }^{2}$ Luminescence Division, Optical Department, Lebedev Physical Institute, 53 Leninsky Prosp., 119991 Moscow, Russia \\ ${ }^{3}$ School of Chemistry, Centre for Synthesis and Chemical Biology, Trinity College Dublin, College Green, Dublin 2, Ireland \\ Correspondence should be addressed to Valentina V. Utochnikova, valentina.utochnikova@gmail.com
}

Received 21 March 2012; Revised 1 May 2012; Accepted 8 May 2012

Academic Editor: Yong Qiu

Copyright ( 2012 Valentina V. Utochnikova et al. This is an open access article distributed under the Creative Commons Attribution License, which permits unrestricted use, distribution, and reproduction in any medium, provided the original work is properly cited.

\begin{abstract}
The new reactive chemical vapor deposition (RCVD) method has been proposed for thin film deposition of luminescent nonvolatile lanthanide aromatic carboxylates. This method is based on metathesis reaction between the vapors of volatile lanthanide dipivaloylmethanate $\left(\mathrm{Ln}(\mathrm{dpm})_{3}\right)$ and carboxylic acid ( $\mathrm{HCarb}$ orH $\left._{2} \mathrm{Carb}^{\prime}\right)$ and was successfully used in case of HCarb. Advantages of the method were demonstrated on example of terbium benzoate $\left(\mathrm{Tb}(\mathrm{bz})_{3}\right)$ and $o$-phenoxybenzoate thin films, and $\mathrm{Tb}(\mathrm{bz})_{3}$ thin films were successfully examined in the OLED with the following structure glass/ITO/PEDOT:PSS/TPD/Tb(bz) $3 / \mathrm{Ca} / \mathrm{Al}$. Electroluminescence spectra of $\mathrm{Tb}(\mathrm{bz})_{3}$ showed only typical luminescent bands, originated from transitions of the terbium ion. Method peculiarities for deposition of compounds of dibasic acids $\mathrm{H}_{2}$ Carb' are established on example of terbium and europium terephtalates and europium 2,6-naphtalenedicarboxylate.
\end{abstract}

\section{Introduction}

A search for new electroluminescent (EL) materials for organic light-emitting diodes (OLEDs) is still an actual challenge for chemists. The solution of it means not only finding a compound which fits the EL material requirements but also the right choice or creation of a technique providing the transformation of such precursors into the thin films of high smoothness and low thickness. This can be demonstrated on examples of lanthanide coordination compounds which are well-known potential luminescent materials $[1-5]$. However, it is not that simple to find among them the luminescent lanthanide coordination compound, which demonstrates simultaneously high thermal and UV stability, bright luminescence, while being volatile or possesses high solubility to deposit thin film of high quality by physical methods from gas phase or solutions. In case of highly volatile $\beta$-diketonates the obvious physical deposition technique allows to obtain thin films of high quality, and their luminescence efficiency can be increased by variation of the substituents in ligands. However these compounds do not exhibit required UV stability. A different situation arises from lanthanide aromatic carboxylates which show high UV, thermal, and chemical stability, as well as high luminescence efficiency, which can reach $100 \%$ in case of $\mathrm{Tb}(\mathrm{bz})_{3}$ [6-9], but for these compounds the choice for the film deposition technique among known methods appears rather impossible. The aromatic carboxylates form extremely rigid 3D networks [10-12], which make them nonvolatile and poorly soluble in organic solvents that complicate deposition of their thin films from gas phase or solution and cause the necessity for search or development of the new methods. Thus, we have proposed the reactive chemical vapor deposition (RCVD) technique for thin films of nonvolatile luminescent lanthanide aromatic carboxylates (HCarb-aromatic monocarboxylic acid) [13, 14]. 


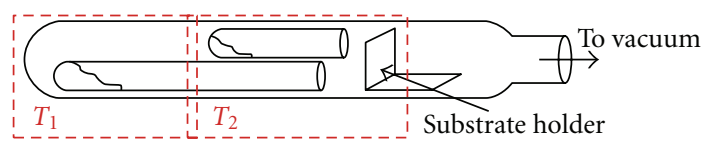

Figure 1: Two temperature zones reactor for gas phase reaction (1).

New RCVD method is based on the gas phase reaction between volatile $\operatorname{Ln}($ dik) 3 (Hdik $=\beta$-diketone $)$ and $\mathrm{HCarb}$ (reaction (1)):

$$
\begin{aligned}
& \operatorname{Ln}(\text { dik })_{3 \text { vapor }}+\mathrm{xHCarb}_{\text {vapor }} \\
& \quad \longrightarrow \mathrm{LnCarb}_{3 \text { solid }}+3 \mathrm{Hdpm}_{\text {vapor }} .
\end{aligned}
$$

The development of RCVD method involved two main steps: (1) study of general principles and (2) elicitation of reaction (1) parameters influencing the quality of thin films deposited (transparency, roughness, thickness, and coating continuity). Lanthanide dipivaloylmethanates, $\operatorname{Ln}(\mathrm{dpm})_{3}$, were selected as precursors because they are known as the most volatile and thermally stable nonfluorinated $\operatorname{Ln}(\mathrm{dik})_{3}$; their vapor consists of mononuclear species only, and temperature dependencies of the saturated vapor pressure have been determined for compounds of all rare earth elements $\left(\mathrm{REE}_{S}\right)[15,16]$. Among monocarboxylic aromatic acids the series of HCarb was first selected to study the gas phase reaction (1), namely, benzoic acid ( $\mathrm{Hbz}$ ) and its $o$-substituted derivatives: salicylic acid (HSal), anthranilic acid (Habz), $N$ phenylanthranilic acid (HPA), and $o$-phenoxybenzoic acid (Hpobz), which differ by chemical stability and volatility [13]. These experiments were run within a horizontal quartz glass reactor with two temperature zones: $T_{1}$ for more volatile HCarb evaporation and $T_{2}$ for less volatile $\operatorname{Ln}(\mathrm{dpm})_{3}$ evaporation and film deposition (Figure 1).

Variation of both $T_{1}$ and $T_{2}$ values allowed us to control the reagents partial vapor pressure ratio during the gas phase reaction. The vapors of HCarb and $\operatorname{Ln}(\mathrm{dpm})_{3}$ converged in the zone $T_{2}$, their interaction occurred, and nonvolatile products deposited on substrate and reactor walls in this hot zone. The composition of products deposited was evaluated by elemental, IR, ${ }^{1} \mathrm{H}$ NMR and luminescent spectroscopy analyses. The following main features of the proposed RCVD method were established: (1) gas phase ligand exchange reaction (1) takes place with a formation of $\operatorname{Ln}(\text { Carb })_{3}$ product; however there is a risk of its incompleteness, which causes product contamination by the $\operatorname{Ln}(\mathrm{Carb})_{3-x}(\mathrm{dpm})_{x}$ impurities; (2) to exclude the formation of these impurities the ratio between the partial vapor pressures of HCarb and $\operatorname{Ln}(\mathrm{dpm})_{3}$ should be $>3: 1$; (3) the temperature $T_{2}$ of the reaction/deposition area should be sufficient to overcome the activation barrier of the reaction but it should not be higher than the temperatures of the decomposition of reactants and product; (4) $\operatorname{Ln}(\mathrm{Carb})_{3-x}(\mathrm{dpm})_{x}$ impurities can be removed by reaction (2) under thermal treatment of the gas phase reaction product in the range of $\operatorname{Ln}(\mathrm{Carb})_{3}$ stability [13]:

$$
\begin{aligned}
& \operatorname{Ln}(\text { Carb })_{3-x}(\mathrm{dpm})_{x} \\
& \quad \longrightarrow(3-x) / 3 \operatorname{Ln}(\text { Carb })_{3}+x / 3 \operatorname{Ln}(\mathrm{dpm})_{3} .
\end{aligned}
$$

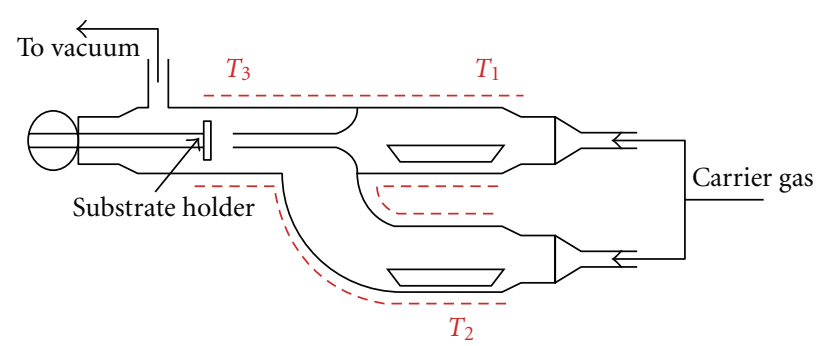

FIGURE 2: Three temperature zones RCVD reactor for thin films deposition.

To control these factors and to reveal their influence on the thin films quality the special RCVD reactor was constructed (Figure 2) [17].

In this reactor the evaporation zones $\left(T_{1}, T_{2}\right)$ and film deposition zone $\left(T_{3}\right)$ were separated, and reagents were transported separately into the deposition zone $T_{3}$ by a stream of carrier gas. The deposition parameters of transparent thin films with uniform composition, morphology, and thickness in the range of $50-100 \mathrm{~nm}$ were found for $\mathrm{Tb}(\mathrm{bz})_{3}$ and $\mathrm{Tb}(\mathrm{pobz})_{3}$. In order to analyze the composition of the thin films the special analytical approach, which corresponded to the combination of luminescent and Raman spectroscopy, was suggested $[14,18]$. It worth noting that the temperatures $\left(T_{1}, T_{2}, T_{3}\right)$ within the RCVD reactor play a crucial role in the composition, transparency, and morphology of $\mathrm{Tb}(\mathrm{Carb})_{3}$ thin films. Therefore, transparent $\mathrm{Tb}(\mathrm{Carb})_{3}$ thin films can be obtained under excessive pressures of HCarb $\left(\mathrm{p}(\mathrm{HCarb}): \mathrm{p}\left(\mathrm{Tb}(\mathrm{dpm})_{3}\right) \gg 3\right)$, which is set by $T_{1} / T_{2}$ ratio, and $T_{3}$ value must be enough for activation of the reaction (2). The variation of $\mathrm{Tb}(\mathrm{Carb})_{3}$ thin film thickness from $200 \mathrm{~nm}$ to $40 \mathrm{~nm}$ is possible by simply decreasing the amount of the reagents within the evaporation zones. Once these principles were fulfilled, it allowed us to deposit high-quality thin films of $\mathrm{Tb}(\mathrm{bz})_{3}$ and $\mathrm{Tb}(\text { pobz })_{3}[14]$.

Here we present new results on EL test of $\mathrm{Tb}(\mathrm{bz})_{3}$ thin films within OLED heterostructure and estimation of proposed RCVD method applicability for deposition of terbium and europium carboxylate thin films derivatives of dibasic acids $\mathrm{H}_{2}$ Carb' such as terephtalic $\left(\mathrm{H}_{2} \mathrm{tph}\right)$ and 2,6naphtalenedicarboxylic $\left(\mathrm{H}_{2} \mathrm{nda}\right)$ acid.

\section{Results and Discussion}

2.1. $\mathrm{Tb}(\mathrm{bz})_{3}$ as EL Layer within OLED. Thin films of $\mathrm{Tb}(\mathrm{bz})_{3}$ deposited using RCVD method in three temperature zone reactor (Figure 2 ) were successfully used in the OLED structure such as glass/ITO/PEDOT:PSS/TPD/Tb(bz) $3 / \mathrm{Ca} / \mathrm{Al}$. EL spectra of $\mathrm{Tb}(\mathrm{bz})_{3}$ showed only typical luminescent bands, originated from transitions of the terbium ion ${ }^{5} \mathrm{D}_{4} \rightarrow{ }^{7} \mathrm{~F}_{J}$ $(J=6-3)$, while no emission of hole transporting layers in the blue region was observed (Figure 3 ).

Thus the efficiency of the RCVD technique was demonstrated for deposition of the thin films for nonvolatile 


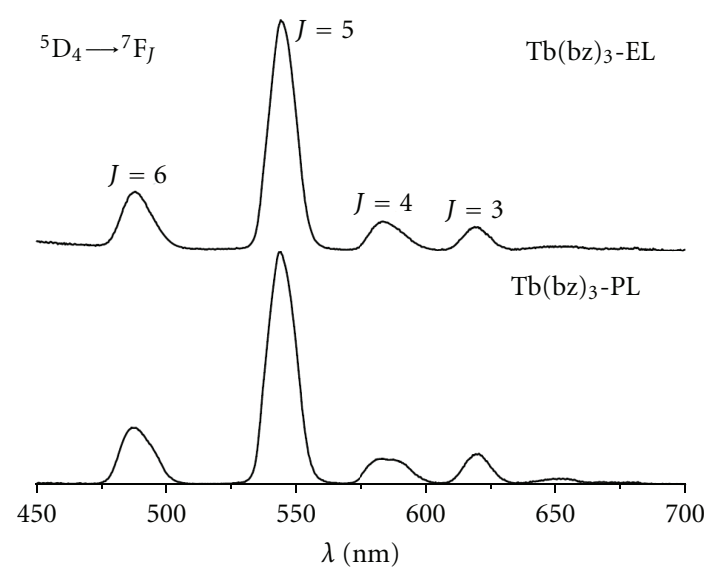

Figure 3: Normalized EL and PL spectra $\left(\lambda_{\text {ex }}=337 \mathrm{~nm}\right)$ of Tb(bz) ${ }_{3}$.

$\mathrm{Tb}(\mathrm{Carb})_{3}$ complexes using highly volatile monobasic aromatic carboxylic acids (HCarb) as a precursors. The $\mathrm{Tb}(\mathrm{bz})_{3}$ films deposited were of such high quality that their use in the OLED structure led to the bright Tb-centered electroluminescence without showing any sublayers luminescence.

2.2. RCVD Method Applicability for Thin Film Deposition of $\mathrm{Tb}$ and $\mathrm{Eu}$ Complexes with $\mathrm{H}_{2} \mathrm{Carb}^{\prime}$. Some lanthanide compounds with aromatic dibasic acids $\mathrm{H}_{2}$ Carb' could be prospective candidates for EL materials due to their bright luminescence and extremely high thermal stability $[6,9]$. Terbium and europium derivatives of terephtalic $\left(\mathrm{H}_{2} \mathrm{tph}\right)$ and 2,6-naphtalenedicarboxylic $\left(\mathrm{H}_{2} \mathrm{nda}\right)$ acids are among the most promising candidates among these compounds; thus they were selected for study of the RCVD applicability for thin film deposition of nonvolatile lanthanide complexes with dibasic acids. The solid state carboxylates $\mathrm{Eu}_{2}(\mathrm{tph})_{3}\left(\mathrm{H}_{2} \mathrm{O}\right)_{4}(\mathrm{I}), \mathrm{Tb}_{2}(\mathrm{tph})_{3}\left(\mathrm{H}_{2} \mathrm{O}\right)_{4}(\mathrm{II})$, $\mathrm{Eu}_{2}$ (nda $)_{3}\left(\mathrm{H}_{2} \mathrm{O}\right)_{6}(\mathrm{III})$, and $\mathrm{Tb}_{2}(\mathrm{nda})_{3}\left(\mathrm{H}_{2} \mathrm{O}\right)_{6}(\mathrm{IV})$ were synthesized according to the traditional method [19], and their luminescent properties and thermal stability were characterized to use them as standards for identification of the gas phase reaction products.

2.2.1. Luminescent Properties and Thermal Stability of the $\mathrm{Ln}_{2}\left(\mathrm{Carb}^{\prime}\right)_{3}\left(\mathrm{H}_{2} \mathrm{O}\right)_{n}$ Solid Samples (I-IV). Luminescent properties of the compounds I-IV were studied in comparison with those of $\mathrm{H}_{2}$ tph and $\mathrm{H}_{2}$ nda. Luminescence spectra of I and II (Figure 4) show only typical ion luminescent bands for both complexes, originated from the electronic transitions of the terbium or europium ions. No emission in the blue region was observed, which is the result of complete energy transfer from the organic part to the central ion. Besides a typical Stark splitting of the terbium emission bands is observed in the spectrum of II.

In case of $\mathrm{Ln}_{2}(\mathrm{nda})_{3}\left(\mathrm{H}_{2} \mathrm{O}\right)_{6}$ only europium complex (III) shows ion luminescence, while in spectrum of terbium complex (IV) there are no terbium luminescence bands present, and a broad band in blue region, originated from the ligand emission, is observed. The hypsochromic shift and narrowing of this band in comparison with $\mathrm{H}_{2}$ nda luminescence band originate from the acid deprotonation and complexation with terbium ion.

The energy of $\mathrm{nda}^{2-}$ triplet level was estimated using the gadolinium compound $\mathrm{Gd}_{2}(\mathrm{nda})_{3}\left(\mathrm{H}_{2} \mathrm{O}\right)_{6}$ phosphorescence spectrum. Unlike europium and terbium complexes, whose luminescence can be sensitized by coordinated ligands, gadolinium compounds do not emit visible light. However, the phosphorescence spectra of these complexes show signals resulting from triplet to singlet transitions and are thus reflecting the triplet state energies of the coordinated ligands [6]. According to the luminescence spectrum of $\mathrm{Gd}_{2}(\mathrm{nda})_{3}\left(\mathrm{H}_{2} \mathrm{O}\right)_{6}$ (Figure S2) (see supplementary material available online at doi:10.1155/2012/809028) excited state level energies of $\mathrm{nda}^{2-}$ are $\mathrm{S}_{1}\left(\mathrm{nda}^{2-}\right)=24200 \mathrm{~cm}^{-1}$, $T_{1}\left(\mathrm{nda}^{2-}\right)=18400 \mathrm{~cm}^{-1}$.

The simplified energy diagram (Figure 5) show that energy of the $\mathrm{nda}^{2-}$ triplet level is high enough only for energy transfer according to the scheme $T_{1}\left(\mathrm{nda}^{2-}\right) \rightarrow$ ${ }^{5} \mathrm{D}_{0}\left(\mathrm{Eu}^{3+}\right)$, while no energy transfer to ${ }^{5} \mathrm{D}_{4}\left(\mathrm{~Tb}^{3+}\right)$ can occur.

In the excitation spectrum of $\mathrm{H}_{2}$ tph two bands are observed ( $\sim 280$ and $\sim 330 \mathrm{~nm}$ ) (Figure 6$)$, which also presented in the spectra of I and II. Besides in the spectra of I and II the low intensity direct ion excitation bands at 360$420 \mathrm{~nm}$ and $350-370 \mathrm{~nm}$, correspondingly, are observed. In the excitation spectrum of $\mathrm{H}_{2}$ nda there are three bands $(\sim 280 \mathrm{~nm}, \sim 370 \mathrm{~nm}$, and $\sim 425 \mathrm{~nm})$. First two bands are also present in the spectrum of III, while the band at $425 \mathrm{~nm}$ is absent, which results from the absence of the energy transfer via the corresponding triplet state. The excitation spectrum of compound IV was recorded in the range of $200-350 \mathrm{~nm}$ since the maximum of its luminescence is $390 \mathrm{~nm}$, and thus only the band at $\sim 280 \mathrm{~nm}$ could be measured.

Thermogravimetric (TG) curves of I-IV were recorded in argon atmosphere and contain two steps of weight loss in all cases: the first step of water molecules elimination and the second step of $\operatorname{Ln}_{2}\left(\text { Carb }^{\prime}\right)_{3}$ decomposition (Figure 7).

In case of $\mathbf{I}$ and $\mathbf{I I}\left(\mathrm{Carb}^{\prime}=\mathrm{tph}\right)$ the residues contained lanthanide oxides $\mathrm{Eu}_{2} \mathrm{O}_{3}$ and $\mathrm{Tb}_{4} \mathrm{O}_{7}$, while III and IV $\left(\mathrm{Carb}^{\prime}=\mathrm{nda}\right)$ could not decompose completely in the inert atmosphere, and the residue most probably is contaminated with carbon.

2.2.2. Gas Phase Synthesis. The reaction providing the gas phase synthesis of $\operatorname{Ln}_{2}\left(\mathrm{Carb}^{\prime}\right)_{3}$ should take place according to $(3)$ :

$$
\begin{aligned}
& 2 \operatorname{Ln}(\mathrm{dpm})_{3 \text { vapor }}+3 \mathrm{H}_{2} \mathrm{Carb}_{\text {vapor }}^{\prime} \\
& \quad \longrightarrow \mathrm{Ln}_{2}\left(\mathrm{Carb}^{\prime}\right)_{3 \text { solid }}+6 \mathrm{Hdpm}_{\text {vapor }} .
\end{aligned}
$$

Brightly luminescent compounds I, II, and III were selected for these syntheses with the aim of their luminescent thin films deposition, but initially reactions (3) were performed in the reactor with two temperature zones (Figure 1).

A choice of the temperature regime providing course of the reaction (3) was based on analysis of the relations between volatility and stability of the starting reagents and products. The stability of $\mathrm{Tb}_{2} \mathrm{Carb}_{3}^{\prime}$ against thermal 


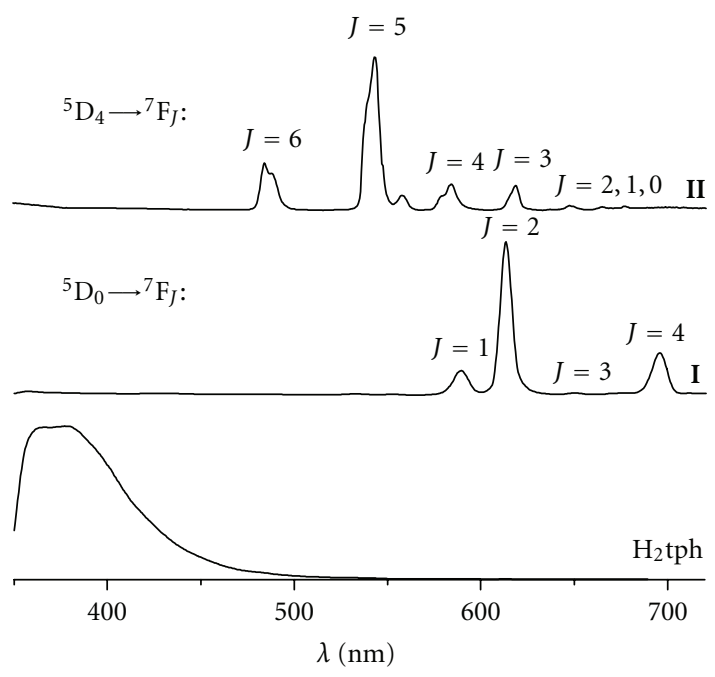

(a)

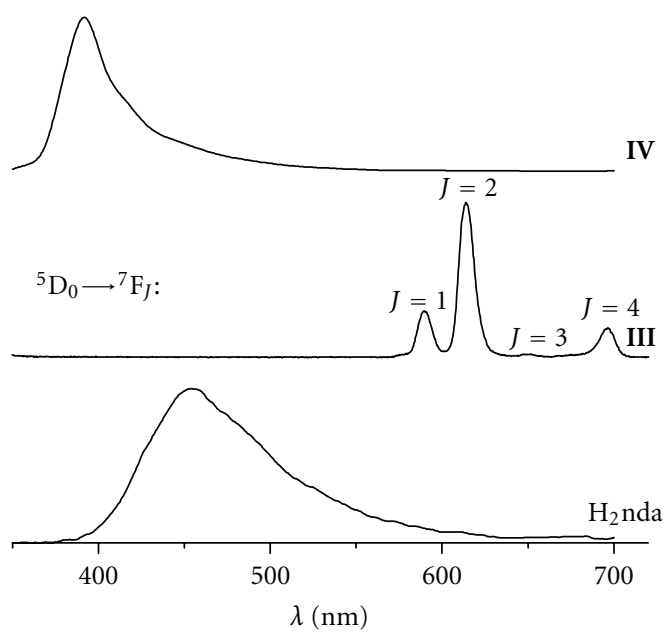

(b)

Figure 4: Normalized luminescence spectra of $\mathrm{H}_{2}$ tph, $\mathrm{Eu}_{2}(\mathrm{tph})_{3}\left(\mathrm{H}_{2} \mathrm{O}\right)_{4}(\mathrm{I}), \mathrm{Tb}_{2}(\mathrm{tph})_{3}\left(\mathrm{H}_{2} \mathrm{O}\right)_{4}(\mathrm{II}), \mathrm{H}_{2} \mathrm{nda}, \mathrm{Eu}_{2}(\mathrm{nda})_{3}\left(\mathrm{H}_{2} \mathrm{O}\right)_{6}(\mathrm{III})$ and $\mathrm{Tb}_{2}(\mathrm{nda})_{3}\left(\mathrm{H}_{2} \mathrm{O}\right)_{6}(\mathrm{IV})\left(\lambda_{\mathrm{ex}}=260 \mathrm{~nm}\right)$.

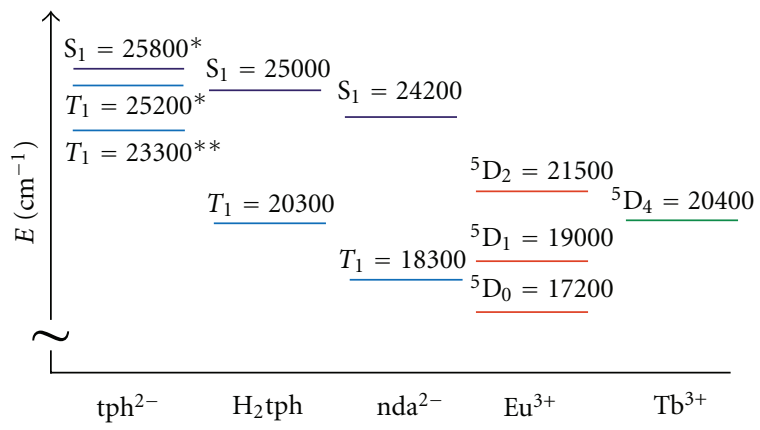

Figure 5: Simplified energy diagram of $\mathrm{Eu}^{3+}, \mathrm{Tb}^{3+}, \mathrm{nda}^{2-}$, and $\mathrm{H}_{2} \mathrm{tph}$, and $\mathrm{tph}^{2-}\left({ }^{*} \mathrm{tph}^{2-}\right.$ energy levels values were taken from [20]; $* * \mathrm{tph}^{2-}$ energy levels values were taken from [6]).

decomposition, determined from thermal analysis data, is rather high: I, II are stable until $400^{\circ} \mathrm{C}$ in inert atmosphere, III-until $600^{\circ} \mathrm{C}$ (Figure 7). $\mathrm{H}_{2}$ tph is stable at least until $>400^{\circ} \mathrm{C}$ even in air [21]. This data is not available for $\mathrm{H}_{2}$ nda; however it can be purified by sublimation at $370^{\circ} \mathrm{C}$ in vacuum $(0.01 \mathrm{mmHg})$ without decomposition, and thus it can be concluded that it is stable at least until this temperature. The data on the dependence between the vapor pressure and temperature for $\mathrm{H}_{2}$ tph and $\mathrm{H}_{2}$ nda is absent in the literature, and therefore volatility of these acids was estimated using thermal analysis in inert atmosphere in comparison with $\mathrm{Hbz}$ (Figure 8). For $\mathrm{Hbz}$ saturated vapor pressure temperature dependence is known [22], and empirical relation between the temperature range of its evaporation in gas phase reaction (1) and half weight loss temperature $\left(T_{1 / 2}\right)$ in TG curve was established.

Thus, the thermogravimetric curves (Figure 8) indicate that the $T_{1 / 2}$ values increase in the row $\mathrm{Hbz}\left(180^{\circ} \mathrm{C}\right)<\mathrm{H}_{2}$ tph $\left(350^{\circ} \mathrm{C}\right)<\mathrm{H}_{2}$ nda $\left(390^{\circ} \mathrm{C}\right)$, which reflects the volatility row.
For $\mathrm{Hbz}$ it was shown $[14,23]$ that temperature of the acid evaporation zone should lie in the range of $\left(T_{1 / 2} \pm\right.$ $100)^{\circ} \mathrm{C}$, and it means that for $\mathrm{H}_{2}$ tph and $\mathrm{H}_{2}$ nda the values of evaporation temperature could not be less than 250 and $300^{\circ} \mathrm{C}$, respectively. According to the mass spectrometry data, $\operatorname{Ln}(\mathrm{dpm})_{3}$ molecules are stable in gas phase only up to $\sim 290^{\circ} \mathrm{C}$, though the Ln-containing species with low partial pressures are present in the gas phase until at least $540^{\circ} \mathrm{C}$ [24]. Thus, $\operatorname{Ln}(\mathrm{dpm})_{3}$ complexes are the least thermal stable reagents that can prevent carrying out reaction (3).

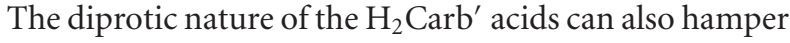
reaction (3). Earlier we have already studied the gas phase synthesis of the lanthanide complexes with diprotic ligands on example of yttrium complex with a Schiff base $\mathrm{H}_{2}$ Salen (from ethylenediamine and salicylic aldehyde) [25]. It was shown that only a mixed-ligand complex of the composition $\mathrm{Y}(\mathrm{dpm})($ Salen $)$ was formed in both gas phase and solution interactions of $\mathrm{Y}(\mathrm{dpm})_{3}$ and $\mathrm{H}_{2}$ Salen even in the excess presence of the last one. We proposed that it resulted from the weak acidity of $\mathrm{H}_{2}$ Salen $\left(\mathrm{pK}_{\mathrm{a}} \sim 11-12,[26]\right)$ contrary to $\mathrm{HCarb}\left(\mathrm{pK}_{\mathrm{a}}=4.21\right.$ for $\left.\mathrm{Hbz}\right)$ and the formation of two sixmembered chelate rings with yttrium ion.

The dibasic acids selected in this work are strong $\left(\mathrm{pK}_{\mathrm{a}}^{1}=\right.$ 3.51 and $\mathrm{pK}_{\mathrm{a}}^{2}=4.82$ for $\mathrm{H}_{2} \mathrm{tph} ; \mathrm{pK}_{\mathrm{a}}^{1}=3.8$ and $\mathrm{pK}_{\mathrm{a}}^{2}=4.7$ for $\mathrm{H}_{2} \mathrm{nda}$ ), and thus we expect that $\mathrm{Ln}_{2} \mathrm{Carb}_{3}^{\prime}$ as a product of the reaction (3) should form.

For the gas phase reaction less volatile $\mathrm{H}_{2} \mathrm{Carb}^{\prime}$ were placed in the hotter zone $T_{2}$ and more volatile $\operatorname{Ln}(\mathrm{dpm})_{3}$-in the colder zone $T_{1}$. For gas phase synthesis of $\mathbf{I}$ the following initial conditions were selected based on both thermal analysis for $\mathrm{H}_{2} \mathrm{tph}$ (Figure 8) and vapor pressure temperature dependences for $\mathrm{Eu}(\mathrm{dpm})_{3}$ data [27]: $T_{1}\left(\mathrm{Eu}(\mathrm{dpm})_{3}\right)=160^{\circ} \mathrm{C}$ and $T_{2}\left(\mathrm{H}_{2} \mathrm{tph}\right)=250^{\circ} \mathrm{C}$. Probably the value of $T_{2}$ was too low for sufficient vapor pressure of $\mathrm{H}_{2} \mathrm{tph}$, and thus the product was not formed. The repeated experiment with 


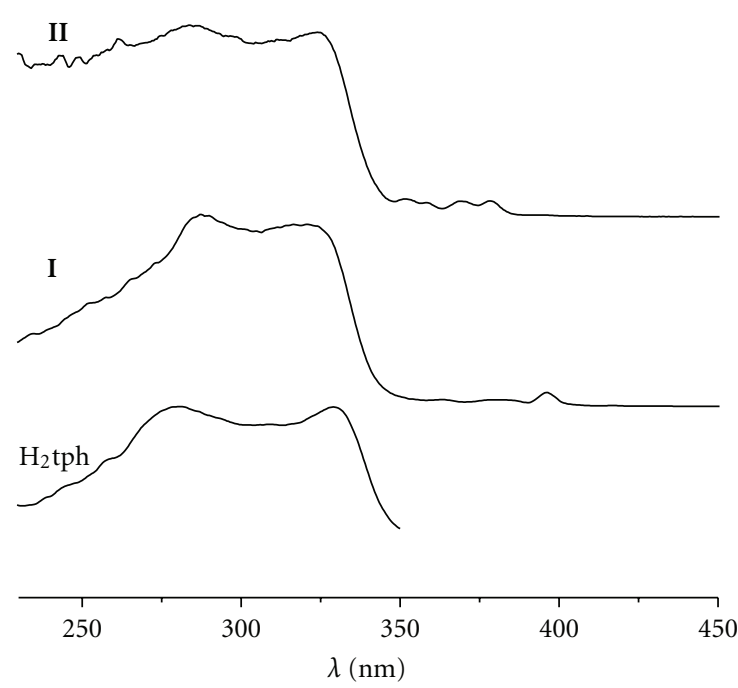

(a)

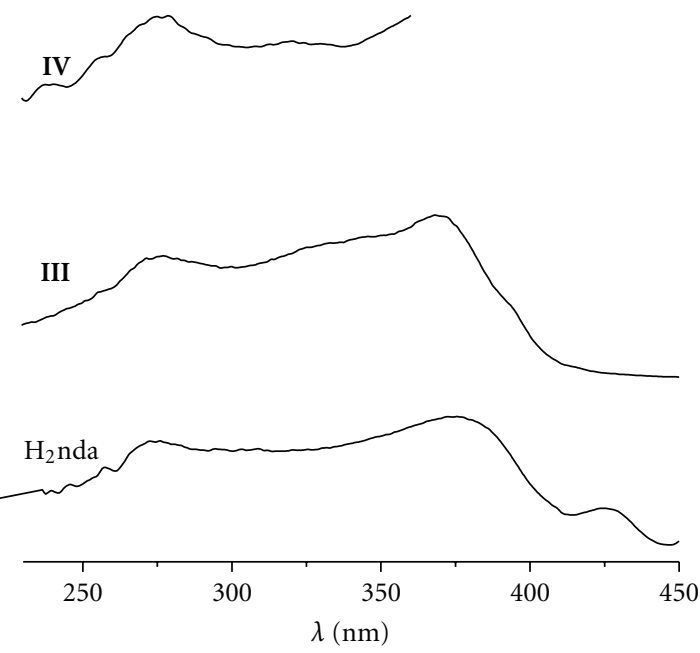

(b)

Figure 6: Normalized excitation spectra of $\mathrm{H}_{2}$ tph $\left(\lambda_{\mathrm{em}}=380 \mathrm{~nm}\right), \mathrm{Eu}_{2}(\mathrm{tph})_{3}\left(\mathrm{H}_{2} \mathrm{O}\right)_{4}\left(\mathbf{I}, \lambda_{\mathrm{em}}=612 \mathrm{~nm}\right), \mathrm{Tb}_{2}(\mathrm{tph})_{3}\left(\mathrm{H}_{2} \mathrm{O}\right)_{4}\left(\mathrm{II}, \lambda_{\mathrm{em}}=\right.$ $545 \mathrm{~nm}), \mathrm{H}_{2} \mathrm{nda}\left(\lambda_{\mathrm{em}}=450 \mathrm{~nm}\right), \mathrm{Eu}_{2}(\mathrm{nda})_{3}\left(\mathrm{H}_{2} \mathrm{O}\right)_{6}\left(\mathrm{III}, \lambda_{\mathrm{em}}=612 \mathrm{~nm}\right)$, and $\mathrm{Tb}_{2}(\mathrm{nda})_{3}\left(\mathrm{H}_{2} \mathrm{O}\right)_{6}\left(\mathrm{IV}, \lambda_{\mathrm{em}}=390 \mathrm{~nm}\right)$.

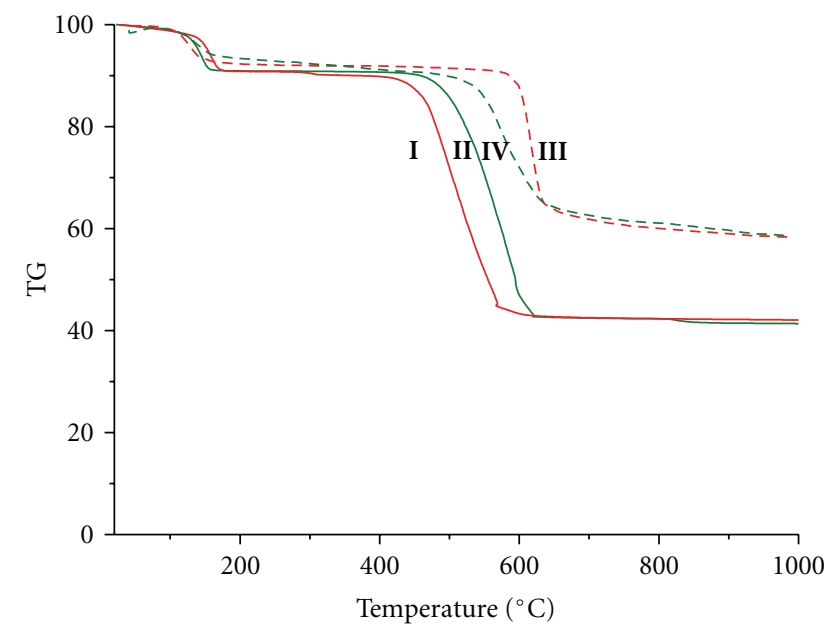

Figure 7: Thermogravimetric curves of $\operatorname{Ln}_{2}\left(\operatorname{Carb}^{\prime}\right)_{3}\left(\mathrm{H}_{2} \mathrm{O}\right)_{n}(\mathbf{I}-\mathbf{I V})$.

$T_{1}\left(\mathrm{Eu}(\mathrm{dpm})_{3}\right)=160^{\circ} \mathrm{C}$ and $T_{2}\left(\mathrm{H}_{2} \mathrm{tph}\right)=300^{\circ} \mathrm{C}$ led to a product formation, but its quantity was extremely low, and it was formed as a thin film (i film) on the surface of glass substrate and reactor walls. The experiment on terbium terephthalate deposition at the same values of $T_{1}$ and $T_{2}$ led to ii film formation.

The emission spectra of both $\mathbf{i}$ and ii films show a broad fluorescence signal with the maximum at $\sim 360 \mathrm{~nm}$ besides the ion luminescence of $\mathrm{Eu}^{3+}$ and $\mathrm{Tb}^{3+}$, which is illustrated in Figure 9 on example of ii film. At the same time excitation spectra demonstrate blue shift of the band edges in comparison with the spectra of I and II concomitantly with the absence of the band at $>350 \mathrm{~nm}$, corresponding to the $\mathrm{dpm}^{-}$-ligand (Figure 9) and thus revealing that the most probable composition of thin films corresponds to the $\mathrm{Ln}_{2} \mathrm{Carb}_{3}\left(\mathrm{H}_{2} \mathrm{Carb}\right)_{x}$. The product of the

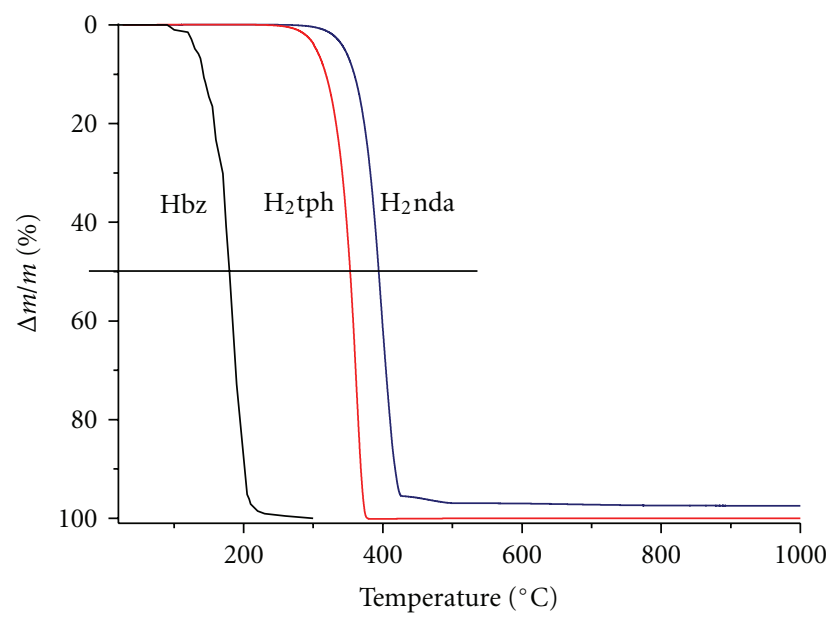

Figure 8: TG curves of $\mathrm{Hbz}, \mathrm{H}_{2}$ tph, and $\mathrm{H}_{2}$ nda.

same composition was also formed by the reaction (3) in solution (see Supplementary Information), which annealing at $360^{\circ} \mathrm{C}$ led to pure $\mathrm{Ln}_{2} \mathrm{Carb}_{3}$ formation. However, during gas phase synthesis it was not possible to increase the $T_{2}$ in order to exclude the acid codeposition into the film, since this temperature is limited by the $\operatorname{Ln}(\mathrm{dpm})_{3}$ stability in the gas phase. Therefore the annealing procedure was used to remove the $\mathrm{H}_{2}$ tph impurity from $\mathbf{i}$ and ii films. Films annealed at $360^{\circ} \mathrm{C}$ for 1 hour did not contain the acid impurities according to both excitation and emission spectra, and their composition corresponded to $\mathrm{Ln}_{2}(\mathrm{tph})_{3}$.

The explanation of the blue shift of the excitation spectra band edges for the thin films containing $\mathrm{H}_{2}$ tph can be found from the estimation of the singlet and triplet energy levels of terephtalic acid from emission spectra of $\mathrm{H}_{2}$ tph (Figure S3). The obtained value of the triplet energy level 


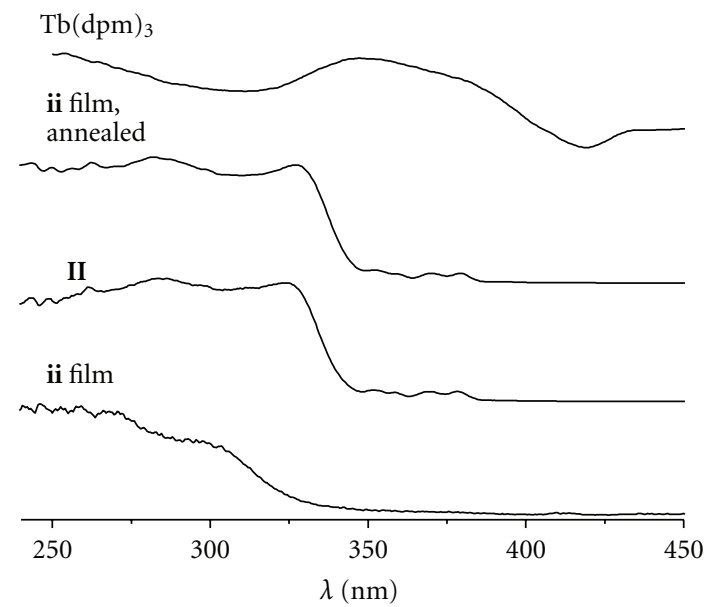

(a)

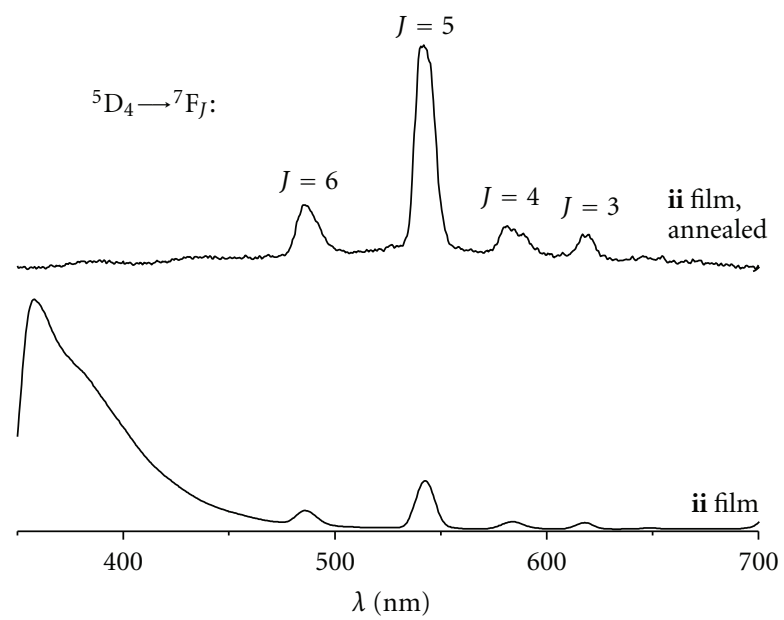

(b)

Figure 9: Normalized (a) excitation spectra of $\mathrm{Tb}_{2}(\mathrm{tph})_{3}\left(\mathrm{H}_{2} \mathrm{O}\right)_{4}(\mathrm{II})$, ii film, ii film annealed, and $\mathrm{Tb}(\mathrm{dpm})_{3}\left(\lambda_{\mathrm{em}}=545 \mathrm{~nm}\right)$, and $(\mathrm{b})$ emission spectra of ii film and ii film annealed $\left(\lambda_{\mathrm{ex}}=280 \mathrm{~nm}\right)$.

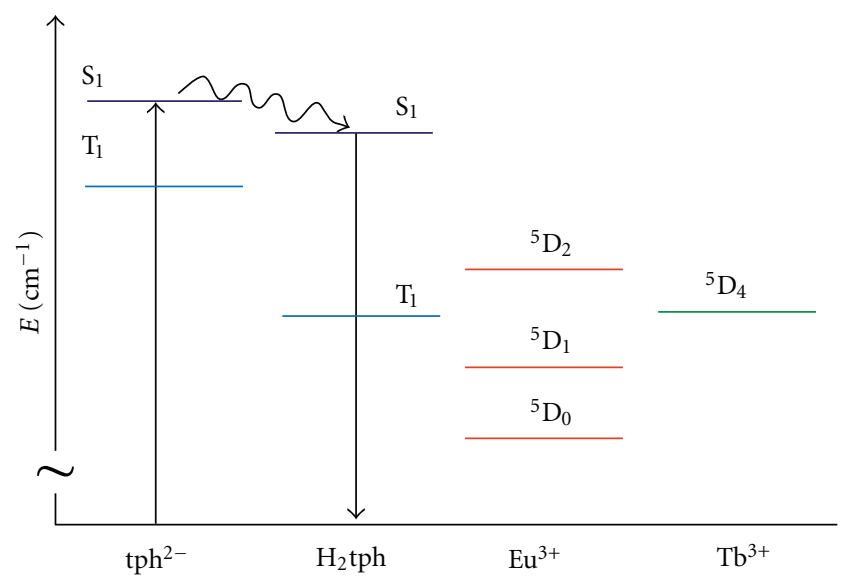

FIGURE 10: Simplified energy diagram showing the energy levels of $\mathrm{tph}^{2-}, \mathrm{H}_{2}$ tph along with $\mathrm{Eu}^{3+}$ and $\mathrm{Tb}^{3+}$.

(Figure 10) shows that in case of europium ion the ligands triplet states and europium resonance levels lie in the row $T_{1}\left(\mathrm{tph}^{2-}\right)>T_{1}\left(\mathrm{H}_{2} \mathrm{tph}\right)>{ }^{5} \mathrm{D}_{1}\left(\mathrm{Eu}^{3+}\right)$ (Figure 10), which means that presence of terephtalic acid should simplify the energy transfer from $\mathrm{tph}^{2-}$ to europium ion. However according to the recorded spectra $\mathrm{H}_{2}$ tph presence is most likely preventing the energy transfer to $\mathrm{Eu}^{3+}$; thus we can conclude that $\mathrm{H}_{2}$ tph triplet state does not at all participate in the energy transfer processes, which could be described according to the scheme, presented in Figure 10.

In the case of terbium containing ii film two possible mechanisms of $\mathrm{H}_{2}$ tph impact on the terbium ion luminescence can be proposed: (1) either $\mathrm{H}_{2}$ tph triplet level can compete with terbium resonance level ${ }^{5} \mathrm{D}_{4}$ during the energy transfer processes or (2) the mechanism can be the same as in case of $\mathbf{i}$ film. Since the observed profiles of excitation spectra of $\mathbf{i}$ and ii films are the same (Figure 11), we can

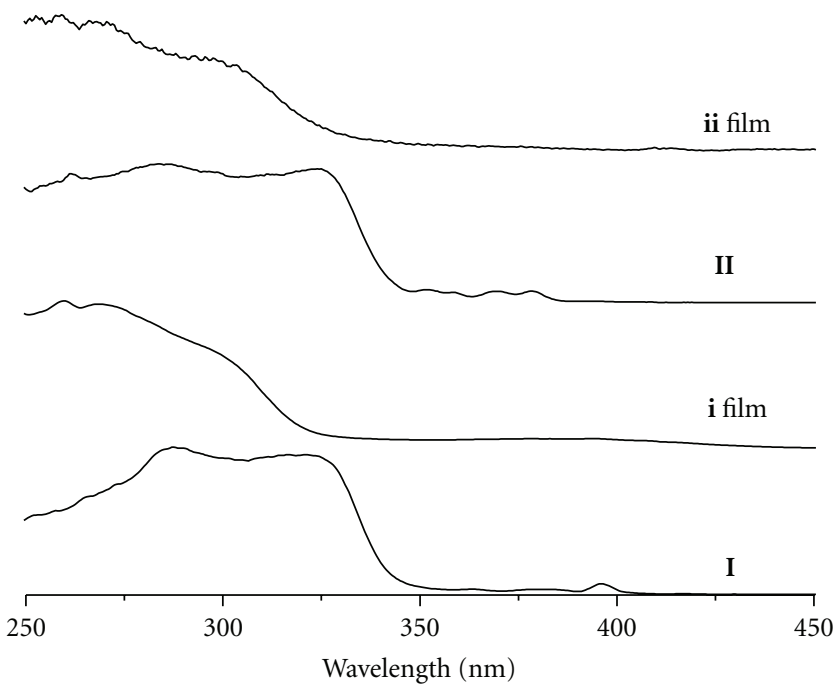

FIgURE 11: Normalized excitation spectra of $\mathrm{Eu}_{2}(\mathrm{tph})_{3}\left(\mathrm{H}_{2} \mathrm{O}\right)_{4}(\mathrm{I})$, $\mathrm{Tb}_{2}(\mathrm{tph})_{3}\left(\mathrm{H}_{2} \mathrm{O}\right)_{4}(\mathrm{II})$, i film, and ii film $\left(\lambda_{\mathrm{em}}=612 \mathrm{~nm}\right.$ for $\mathbf{I}$ and $\mathbf{i}$ film, $\lambda_{\mathrm{em}}=545 \mathrm{~nm}$ for II and ii film).

suggest that the scheme of $\mathrm{H}_{2}$ tph participation in the energy transfer in case of terbium compound is similar to that one for europium compound (Figure 10). Elimination of $\mathrm{H}_{2} \mathrm{tph}$ after annealing results in the band edge for thin films being identical to the reference solid state samples I or II (Figure 9) and proves the formation of the pure $\mathrm{Ln}_{2}(\mathrm{tph})_{3}$ films.

Since volatility of $\mathrm{H}_{2}$ nda is lower than of $\mathrm{H}_{2}$ tph, the gas phase reaction (3) with $\mathrm{H}_{2}$ nda was performed at higher temperature $T_{2}\left(\mathrm{H}_{2} \mathrm{nda}\right)=370^{\circ} \mathrm{C}$ and the same temperature $T_{1}\left(\operatorname{Eu}(\mathrm{dpm})_{3}\right)=160^{\circ} \mathrm{C}$, which led to the iii film deposition. According to the luminescence spectra (Figure 12) this film was also contaminated with codeposited acid $\mathrm{H}_{2} \mathrm{nda}$, which was removed after annealing at $370^{\circ} \mathrm{C}$ for 1 hour. 
TABLE 1: Experimental conditions of gas phases syntheses.

\begin{tabular}{|c|c|c|c|c|c|}
\hline No., Ln & $T_{1}\left(\mathrm{H}_{2} \mathrm{Carb}^{\prime}\right),{ }^{\circ} \mathrm{C}$ & $T_{2}\left(\operatorname{Ln}(\mathrm{dpm})_{3}\right),{ }^{\circ} \mathrm{C}$ & $m_{1}\left(\mathrm{H}_{2} \mathrm{Carb}^{\prime}\right), \mathrm{g}$ & $m_{2}\left(\operatorname{Ln}(\mathrm{dpm})_{3}\right), \mathrm{g}$ & Product assignment \\
\hline \multicolumn{6}{|c|}{$\mathrm{H}_{2} \mathrm{Carb}^{\prime}=\mathrm{H}_{2}$ tph } \\
\hline 1, Eu & 160 & 250 & 0.58 & 0.075 & $\mathrm{~N} / \mathrm{A}$ \\
\hline 2, Eu & 160 & 300 & 0.71 & 0.068 & i film \\
\hline $3, \mathrm{~Tb}$ & 160 & 300 & 0.82 & 0.097 & ii film \\
\hline \multicolumn{6}{|c|}{$\mathrm{H}_{2}$ Carb $^{\prime}=\mathrm{H}_{2}$ nda } \\
\hline 4, Eu & 160 & 370 & 0.50 & 0.500 & iii film \\
\hline
\end{tabular}

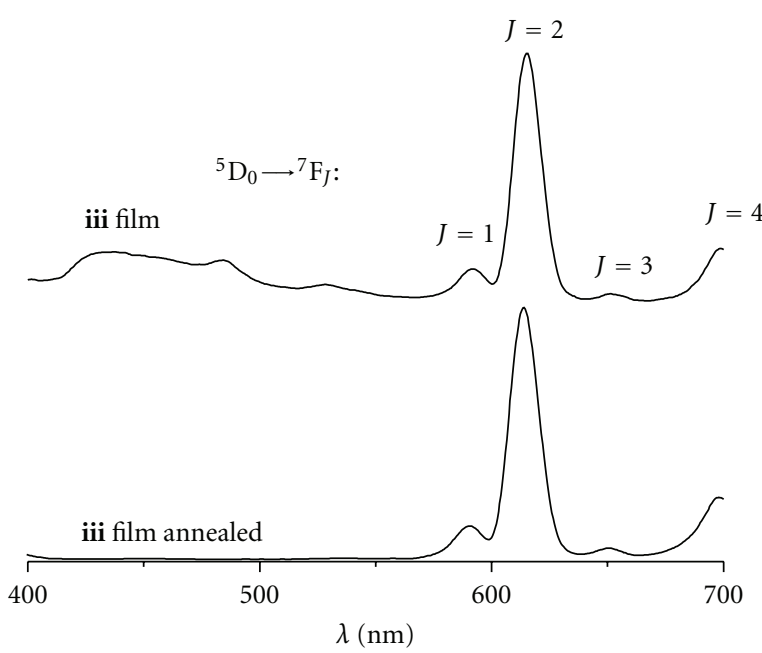

FIGURE 12: Normalized emission spectra of iii film and iii annealed film $\left(\lambda_{\mathrm{ex}}=260 \mathrm{~nm}\right)$.

Thus the metathesis reaction (3) between $\operatorname{Ln}(\mathrm{dpm})_{3}$ and dibasic acids $\mathrm{H}_{2} \mathrm{Carb}^{\prime}$ takes place in the gas phase, which was shown on example of $\mathrm{H}_{2} \mathrm{Carb}^{\prime}=\mathrm{H}_{2} \mathrm{tph}, \mathrm{H}_{2}$ nda. However, due to the low volatility of these acids it is necessary to significantly increase the temperature of their evaporation in order to assure the vapor pressure. Simultaneously the raise of this temperature leads to the risk of $\operatorname{Ln}(\mathrm{dpm})_{3}$ thermal decomposition in hot zone of the reactor. This mismatch of the temperature ranges of $\operatorname{Ln}(\mathrm{dpm})_{3}$ stability in gas phase and $\mathrm{H}_{2} \mathrm{Carb}^{\prime}$ volatility results in the low yield of the product and the unsteadiness of the gas phase reaction, which cannot be excluded even by using the three-zone reactor. Thus gas phase reaction (3) takes place but is significantly hampered by the low volatility of $\mathrm{H}_{2} \mathrm{Carb}^{\prime}$.

\section{Conclusion}

In conclusion we presented here the reactive chemical vapor deposition (RCVD) method for thin film deposition of nonvolatile aromatic carboxylates, based on metathesis reaction between volatile $\operatorname{Ln}(\mathrm{dpm})_{3}$ and aromatic carboxylic acids. The advantages of this method for deposition of thin films of lanthanide derivatives of the highly volatile monobasic acids were demonstrated on examples of terbium benzoate and $o$-phenoxybenzoate. The thin films of high quality were deposited which allowed us to use them for OLED manufacturing on the example of $\mathrm{Tb}(\mathrm{bz})_{3}$-based OLED with the structure glass/ITO/PEDOT:PSS/TPD/Tb $(\mathrm{bz})_{3} / \mathrm{Ca} / \mathrm{Al}$. The RCVD method was examined for deposition of the thin films of luminescent lanthanide derivatives of low-volatile dibasic carboxylic acids $\mathrm{H}_{2}$ tph and $\mathrm{H}_{2}$ nda. Here, the use of this method is complicated by the low volatility of the selected acids due to the mismatch of the temperature ranges of $\operatorname{Ln}(\mathrm{dpm})_{3}$ stability in gas phase and $\mathrm{H}_{2}$ Carb $^{\prime}$ volatility. Thus RCVD method is perspective for highly volatile acids derivatives deposition and is significantly hampered in case of low volatile acids.

\section{Experimental Part}

Commercial dipivaloylmethane (Hdpm, Fluka) and pure for analysis grade terbium, europium, and gadolinium nitrate hexahydrates, sodium hydroxide $(\mathrm{NaOH})$, and terephtalic acid $\left(\mathrm{H}_{2} \mathrm{tph}\right.$, Acros organics) were used as received. Naphthalenedicarboxylic acid $\left(\mathrm{H}_{2} \mathrm{nda}\right)$ and benzoic acid $(\mathrm{Hbz})$ were purified by vacuum sublimation $(0.01 \mathrm{mmHg})$ at 370 and $80^{\circ} \mathrm{C}$, respectively.

The elemental analysis of complexes was carried out on a $\mathrm{C}, \mathrm{H}, \mathrm{N}$-analyzer of the Organic Chemistry Division, Chemical Department, Lomonosov Moscow State University. Thermal analysis was carried out on a thermoanalyzer STA 409 PC Luxx (NETZSCH, Germany) in the temperature range of $20-1000^{\circ} \mathrm{C}$ in argon atmosphere, heating rate $10^{\circ} \mathrm{min}$. Photoluminescence and excitation spectra were measured on Perkin-Elmer LS-55 luminescence spectrometer utilizing with a xenon lamp with a tunable wavelength as an excitation source at $25^{\circ} \mathrm{C}$ as well as multichannel spectrometer S2000 (Ocean Optics) with a nitrogen laser LGI-21 $\left(\lambda_{\text {ex }}=337 \mathrm{~nm}\right)$ as an excitation source at $77 \mathrm{~K}$. All emission and excitation spectra were corrected for the instrumental functions. The triplet state energy was estimated from maximum of the broad not resolved phosphorescence band in $\mathrm{Gd}_{2}(\mathrm{nda})_{3}\left(\mathrm{H}_{2} \mathrm{O}\right)_{6}$ and $\mathrm{H}_{2}$ tph luminescence spectra at $77 \mathrm{~K}$, distinguished from the second short-wave band, attributed to fluorescence (Figures S2 and S3).

The complexes $\mathrm{Ln}(\mathrm{dpm})_{3} \cdot 2 \mathrm{H}_{2} \mathrm{O}(\mathrm{Ln}=\mathrm{Eu}, \mathrm{Tb})$ were synthesized and characterized by a standard procedure [15, 16]. Anhydrous $\operatorname{Ln}(\mathrm{dpm})_{3}$ were obtained by sublimation of the hydrated complexes in vacuum $(0.01 \mathrm{mmHg})$ at 120 $150^{\circ} \mathrm{C}$. 
OLED manufacturing took place in a clean room class 10000 (Lebedev Physical Institute, Moscow, Russia) in a glovebox with argon atmosphere. Thin films of PEDOT:PSS with thickness $\sim 30 \mathrm{~nm}$ were obtained by spin-coating. TPD layer was thermally evaporated (Univex-300, LeybordHeraeus) under a pressure below $10^{-6} \mathrm{mmHg}$. The thickness was $\sim 40 \mathrm{~nm}$ controlled by quartz indicator. Emitting layer $\left(\mathrm{Tb}(\mathrm{bz})_{3}\right)$ was deposited using $\mathrm{RCVD}$ technique at $T_{1}\left(\mathrm{~Tb}(\mathrm{dpm})_{3}\right)=125^{\circ} \mathrm{C}, \mathrm{T}_{2}(\mathrm{Hbz})=140^{\circ} \mathrm{C}, T_{3}=250^{\circ} \mathrm{C}$. The contacts were attached to the electrodes, and the device was sealed with epoxy resin. Electroluminescence spectra were measured on a PicoQuant time-correlated single photon counting system used as a conventional spectrofluorimeter. Spectral resolution was $4 \mathrm{~nm}$.

4.1. Synthesis of $\operatorname{Ln}_{2}\left(\mathrm{Carb}^{\prime}\right)_{3}\left(\mathrm{Ln}=\mathrm{Eu}, \mathrm{Tb} ; \mathrm{H}_{2} \mathrm{Carb}^{\prime}=\mathrm{H}_{2} \mathrm{tph}\right.$, $\left.\mathrm{H}_{2} n d a\right) . \mathrm{Ln}_{2}\left(\mathrm{Carb}^{\prime}\right)_{3} \cdot n \mathrm{H}_{2} \mathrm{O}(n=4,6)$ were synthesized by a standard procedure [19] by the reaction of water solutions of $\mathrm{Tb}\left(\mathrm{NO}_{3}\right)_{3} \cdot 6 \mathrm{H}_{2} \mathrm{O}(1 \mathrm{mmol})$ and of $\mathrm{K}_{2}\left(\mathrm{Carb}^{\prime}\right)(1.5 \mathrm{mmol}$, from $\mathrm{KOH}$ and $\left.\mathrm{H}_{2} \mathrm{Carb}^{\prime}\right)$.

$\mathrm{Eu}_{2}(\mathrm{tph})_{3}\left(\mathrm{H}_{2} \mathrm{O}\right)_{4}(\mathrm{I})$ : for $\mathrm{Eu}_{2} \mathrm{C}_{24} \mathrm{H}_{20} \mathrm{O}_{16}(M=868)$ anal. calcd. (\%): C, 33.2; H, 2.3. Found (\%): C, 30.7; H, 2.5.

IR spectrum, $\mathrm{cm}^{-1}: 3200-3600(\nu(\mathrm{O}-\mathrm{H})), 3065(\nu(\mathrm{C}-$ $\mathrm{H})), 2982(\nu(\mathrm{C}-\mathrm{H})), 2900(\nu(\mathrm{C}-\mathrm{H})), 1590(\delta(\mathrm{C}-\mathrm{C})), 1541$ $\left(\nu_{\text {as. }}(\mathrm{COO})\right), 1505,1410,1420$.

$\mathrm{Tb}_{2}(\mathrm{tph})_{3}\left(\mathrm{H}_{2} \mathrm{O}\right)_{4}(\mathrm{II})$ : for $\mathrm{Tb}_{2} \mathrm{C}_{24} \mathrm{H}_{20} \mathrm{O}_{16}(M=882)$ anal. calcd. (\%): C, 32.7; H, 2.4. Found (\%): C, 32.7; H, 2.6.

Raman spectrum, $\mathrm{cm}^{-1}: 3067(\mathrm{C}-\mathrm{H}), 1612$ s. (C-C arom. $), 1529$ ( $\left.\mathrm{COO}_{\mathrm{as}}^{-}\right), 1456$ s. $\left(\mathrm{COO}_{\text {sym }}^{-}\right), 1310,1145,869$ s., 629.

IR spectrum, $\mathrm{cm}^{-1}: 3200-3600(\nu(\mathrm{O}-\mathrm{H})), 3063(\nu(\mathrm{C}-$ $\mathrm{H})), 2983(\nu(\mathrm{C}-\mathrm{H})), 2903(\nu(\mathrm{C}-\mathrm{H})), 1587(\delta(\mathrm{C}-\mathrm{C})), 1541$ $\left(\nu_{\text {as. }}(\mathrm{COO})\right), 1504,1402,1424$.

$\mathrm{Eu}_{2}$ (nda) $)_{3}\left(\mathrm{H}_{2} \mathrm{O}\right)_{6}(\mathrm{III})$ : for $\mathrm{Eu}_{2} \mathrm{C}_{36} \mathrm{H}_{30} \mathrm{O}_{18}(M=1054)$ anal. calcd. (\%): C, 40.8; H, 2.9. Found (\%): C, 40.8; H, 2.8.

Raman spectrum, $\mathrm{cm}^{-1}: 1632$ (C-C arom.), 1487 $\left(\mathrm{COO}^{-}\right), 1439\left(\mathrm{COO}^{-}\right), 1394,1122,784,523$.

IR spectrum, $\mathrm{cm}^{-1}: 3200-3600(\nu(\mathrm{O}-\mathrm{H})), 3059(\nu(\mathrm{C}-$ $\mathrm{H})), 2970(\nu(\mathrm{C}-\mathrm{H})), 2913(\nu(\mathrm{C}-\mathrm{H})), 1605(\delta(\mathrm{C}-\mathrm{C})), 1540$ $\left(\nu_{\text {as. }}(\mathrm{COO})\right), 1490,1409,1358$.

$\mathrm{Gd}_{2}(\mathrm{nda})_{3}\left(\mathrm{H}_{2} \mathrm{O}\right)_{6}$ : for $\mathrm{Gd}_{2} \mathrm{C}_{36} \mathrm{H}_{30} \mathrm{O}_{18}(M=1064)$ anal. calcd. (\%): C, 40.0; H, 2.8. Found (\%): C, 40.8; H, 2.8 .

IR spectrum, $\mathrm{cm}^{-1}: 3200-3600(\nu(\mathrm{O}-\mathrm{H})), 3060(\nu(\mathrm{C}-$ $\mathrm{H})), 2973(\nu(\mathrm{C}-\mathrm{H})), 2910(\nu(\mathrm{C}-\mathrm{H})), 1607(\delta(\mathrm{C}-\mathrm{C})), 1544$ $\left(\nu_{\text {as. }}(\mathrm{COO})\right), 1493,1410,1353$.

$\mathrm{Tb}_{2}(\mathrm{nda})_{3}\left(\mathrm{H}_{2} \mathrm{O}\right)_{6}(\mathrm{IV})$ : for $\mathrm{Tb}_{2} \mathrm{C}_{36} \mathrm{H}_{30} \mathrm{O}_{18} \quad(M=1068)$ anal. calcd. (\%): C, 39.1; H, 2.8. Found (\%): C, 40.5; H, 2.9.

IR spectrum, $\mathrm{cm}^{-1}: 3200-3600(\nu(\mathrm{O}-\mathrm{H})), 3073(\nu(\mathrm{C}-$ $\mathrm{H})), 2887(\nu(\mathrm{C}-\mathrm{H})), 2829(\nu(\mathrm{C}-\mathrm{H})), 1602(\delta(\mathrm{C}-\mathrm{C})), 1544$ $\left(\nu_{\text {as. }}(\mathrm{COO})\right), 1490,1410,1360$.

4.2. Gas Phase Reaction of $\operatorname{Ln}(\mathrm{dpm})_{3}$ and $\mathrm{H}_{2} \mathrm{Carb}^{\prime}\left(\mathrm{H}_{2} \mathrm{Carb}^{\prime}=\right.$ $\left.\mathrm{H}_{2} t p h, \mathrm{H}_{2} n d a ; \mathrm{Ln}=\mathrm{Eu}, \mathrm{Tb}\right)$. The gas phase reaction of $\mathrm{Ln}(\mathrm{dpm})_{3}$ with appropriate $\mathrm{H}_{2} \mathrm{Carb}^{\prime}$ was carried out under reduced pressure $(0.01 \mathrm{~mm} \mathrm{Hg})$ in a horizontal glass reactor with two temperature zones $\left(T_{1}\right.$ and $\left.T_{2}\right)$ (Figure 1$)$. The unreacted volatile reactants were collected in the zone maintained at room temperature. The nonvolatile reaction products condensed in the reactor zone with the temperature $T_{2}$.

The time of experiments was $60 \mathrm{~min}$. The values of temperatures of the reaction zones and masses of the reagents are summarized in Table 1.

\section{Acknowledgments}

The authors thank the Ministry of Education and Science of Russian Federation (contract no. 16.516.11.6071) for the financial support.

\section{References}

[1] K. Binnemans, "Lanthanide-based luminescent hybrid materials," Chemical Reviews, vol. 109, no. 9, pp. 4283-4374, 2009.

[2] L. D. Carlos, R. A. S. Ferreira, V. de Zea Bermudez, B. Julian-Lopez, and P. Escribano, "Progress on lanthanidebased organic-inorganic hybrid phosphors," Chemical Society Reviews, vol. 40, no. 2, pp. 536-549, 2011.

[3] S. V. Eliseeva and J. C. G. Bünzli, "Rare earths: Jewels for functional materials of the future," New Journal of Chemistry, vol. 35, no. 6, pp. 1165-1176, 2011.

[4] A. De Bettencourt-Dias, "Lanthanide-based emitting materials in light-emitting diodes," Dalton Transactions, no. 22, pp. 2229-2241, 2007.

[5] M. A. Katkova and M. N. Bochkarev, "New trends in design of electroluminescent rare earth metallo-complexes for OLEDs," Dalton Transactions, vol. 39, no. 29, pp. 6599-6612, 2010.

[6] M. Hilder, P. C. Junk, U. H. Kynast, and M. M. Lezhnina, "Spectroscopic properties of lanthanoid benzene carboxylates in the solid state: part 1," Journal of Photochemistry and Photobiology A, vol. 202, no. 1, pp. 10-20, 2009.

[7] M. Hilder, M. Lezhnina, M. L. Cole, C. M. Forsyth, P. C. Junk, and U. H. Kynast, "Spectroscopic properties of lanthanoid benzene carboxylates in the solid state: part 2. Polar substituted benzoates," Journal of Photochemistry and Photobiology A, vol. 217, no. 1, pp. 76-86, 2011.

[8] M. Bredol, U. Kynast, and C. Ronda, "Designing luminescent materials," Advanced Materials, vol. 3, no. 7-8, pp. 361-367, 1991.

[9] R. Łyszczeka, Z. Rzą̧czyńska, A. Kula, and A. Gładysz-Płaska, "Thermal and luminescence characterization of lanthanide 2,6-naphthalenedicarboxylates series," Journal of Analytical and Applied Pyrolysis, vol. 92, no. 2, pp. 347-354, 2011.

[10] L. Armelao, S. Quici, F. Barigelletti et al., "Design of luminescent lanthanide complexes: From molecules to highly efficient photo-emitting materials," Coordination Chemistry Reviews, vol. 254, no. 5-6, pp. 487-505, 2010.

[11] Y. E. Alexeev, B. I. Kharisov, T. C. H. García, and A. D. Garnovskii, "Coordination motifs in modern supramolecular chemistry," Coordination Chemistry Reviews, vol. 254, no. 7-8, pp. 794-831, 2010.

[12] S. Qiu and G. Zhu, "Molecular engineering for synthesizing novel structures of metal-organic frameworks with multifunctional properties," Coordination Chemistry Reviews, vol. 253, no. 23-24, pp. 2891-2911, 2009.

[13] V. V. Utochnikova, O. V. Kotova, E. M. Shchukina, S. V. Eliseeva, and N. P. Kuz'mina, "Gas-phase synthesis of terbium and lutetium carboxylates," Russian Journal of Inorganic Chemistry, vol. 53, no. 12, pp. 1878-1884, 2008. 
[14] O. V. Kotova, V. V. Utochnikova, S. V. Samoylenkov, A. D. Rusin, L. S. Lepnev, and N. P. Kuzmina, "Reactive chemical vapour deposition (RCVD) of non-volatile terbium aromatic carboxylate thin films," Journal of Materials Chemistry, vol. 22, no. 11, pp. 4897-4903, 2012.

[15] K. J. Eisentraut and R. E. Sievers, "Volatile rare earth chelates," Journal of the American Chemical Society, vol. 87, no. 22, pp. 5254-5256, 1965.

[16] C. Görller-Walrand and K. Binnemans, "Rationalization of crystal-field parametrization," in Handbook on the Physics and Chemistry of Rare Earths, K. A. Gschneidner Jr. and L. Eyring, Eds., vol. 23, Chapter 153, pp. 121-283, NorthHolland, Amsterdam, The Netherlands, 1996.

[17] S. V. Samoilenkov, O. V. Kotova, N. P. Kuzmina, L. S. Lepnev, and A. G. Vitukhnovskii, "Method of making thin films of chemical compounds and installation for realising said method," Patent Application Russia, CODEN: RUXXE7, RU2388770, 2010.

[18] O. Kotova, S. Eliseeva, R. Muydinov, N. Kuzmina, and A. Kaul, "MOCVD application for thin film deposition of nonvolatile lanthanide carboxylates," Proceedings Volumes of The Electrochemical Society, vol. 9, pp. 306-311, 2005.

[19] Gmelin Handbook of Inorganic Chemistry, System no. 39, vol. D4, Springer, Berlin, Germamy, 1984.

[20] Z. Wang, Y. Yang, Y. Cui, Z. Wang, and G. Qian, "Colortunable and white-light emitting lanthanide complexes based on $\left(\mathrm{Ce}_{x} \mathrm{Eu}_{y} \mathrm{~Tb}_{1-x-y}\right)_{2}(\mathrm{BDC})_{3}\left(\mathrm{H}_{2} \mathrm{O}\right)_{4}$, "Journal of Alloys and Compounds, vol. 510, no. 1, pp. L5-L8, 2011.

[21] ICI Chemicals and Polymers Limited, Product Safety Data: Pure Terephthalic Acid, 1991.

[22] T. E. Jordan, Vapor Pressure of Organic Compounds, Interscience, London, UK, 1954.

[23] O. V. Kotova, V. V. Utochnikova, S. V. Eliseeva, S. V. Samoilenkov, and N. P. Kuz'mina, "Gas-phase synthesis of lanthanide(III) benzoates $\operatorname{Ln}(\mathrm{Bz})_{3}(\mathrm{Ln}=\mathrm{La}, \mathrm{Tb}, \mathrm{Lu})$," Russian Journal of Coordination Chemistry, vol. 33, no. 6, pp. 454-457, 2007.

[24] G. V. Girichev, N. I. Giricheva, N. V. Belova, A. R. Kaul, N. P. Kuzmina, and O. Yu. Gorbenko, "Yttrium dipivaloylmethanate thermal stability study using mass-spectrometry method," Russian Journal of Inorganic Chemistry, vol. 38, p. 2, 1993.

[25] V. V. Utochnikova, O. V. Kotova, and N. P. Kuz'mina, “Solution and gas-phase synthesis of the heteroligand yttrium complex with dipivaloylmethane and bis(salicylidene)ethylenediamine $\mathrm{Y}(\mathrm{dpm})($ salen)," Moscow University Chemistry Bulletin, vol. 62, no. 4, pp. 226-229, 2007.

[26] F. Lloret, M. Mollar, J. Faus, M. Julve, I. Castro, and W. Diaz, "Solution chemistry of N,N'-ethylenebis(salicylideneimine) and its copper(II), nickel(II) and iron(III) complexes," Inorganica Chimica Acta, vol. 189, no. 2, pp. 195-206, 1991.

[27] J. E. Sicre, J. T. Dubois, K. J. Eisentraut, and R. E. Sievers, "Volatile lanthanide chelates. II. Vapor pressures, heats of vaporization, and heats of sublimation," Journal of the American Chemical Society, vol. 91, no. 13, pp. 3476-3481, 1969. 

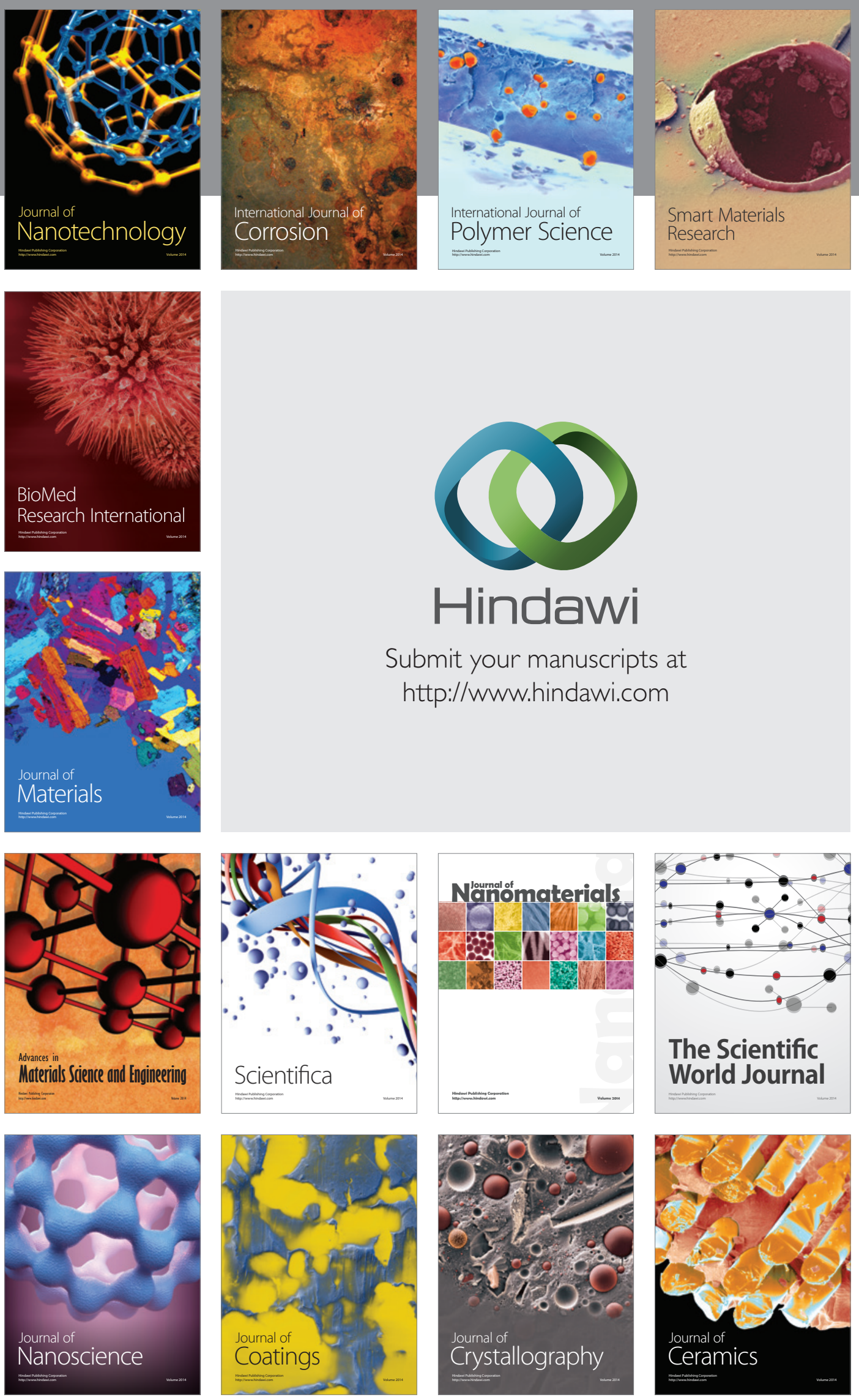

The Scientific World Journal

Submit your manuscripts at

http://www.hindawi.com

\section{World Journal}

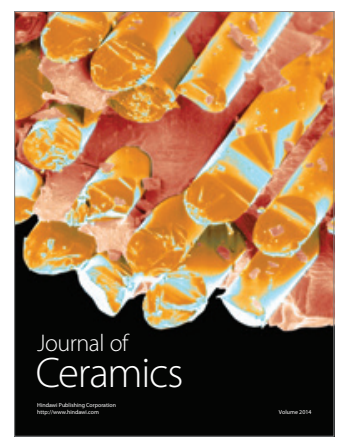

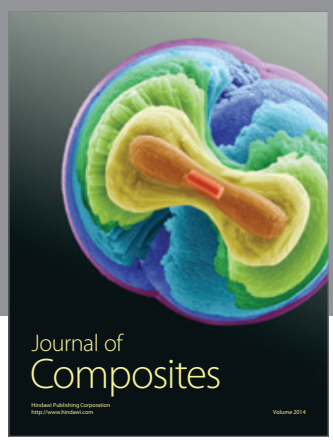
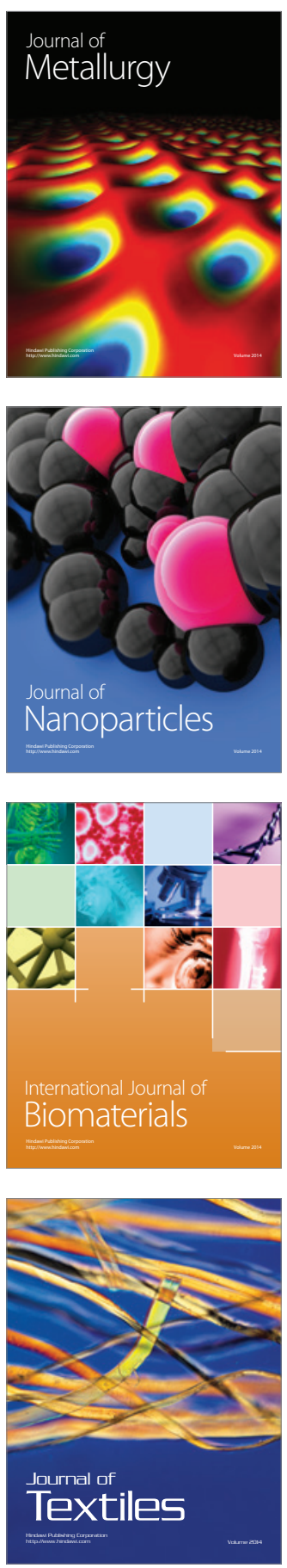